\title{
Comparing metal uptake by vegetation under different experimental conditions
}

\author{
D. Sinnett, R. van Herwijnen, C. Kilbride \& T. R. Hutchings \\ Land Regeneration and Urban Greening Research Group, \\ Forest Research, UK
}

\begin{abstract}
Modern planning policies recognise that the provision of green space such as parkland and community woodland offer multifunctional environmental and social benefits which can contribute strongly to the sustainability of towns and cities. A challenge to such development is that the soils of many former industrial sites often contain elevated concentrations of contaminants including potentially toxic elements, for example metals. The bioavailability of metals can be reduced in the contaminated soil prior to greenspace establishment, thus reducing their risk to ecosystems and human health. For the establishment of a safe greenspace in the perspective of the contaminant receptor pathway linkage an understanding of the uptake, compartmentation and toxicological effects of these contaminants to vegetation is important.

We have collated data from hydroponic and contaminated soil pot trials and from field trials on contaminated sites. The data have been used to produce correlations between heavy metal availability, plant uptake and compartmentation of the heavy metals for poplar Fritzi Pauley. From the correlations, models for plant uptake are provided with an assessment on the impact of improved soil conditions and consequent improved plant performance and the metal uptake by these plants. This information may be used to assess the risk for receptors after potential greenspace establishment on heavy metal contaminated soil.

Keywords: Cd, Zn, poplar, metal compartmentation, plant uptake.
\end{abstract}




\section{Introduction}

Greenspace creation has become an increasingly attractive option for the development of former industrial sites. Many sites are found in areas that may have suffered economic decline in recent decades, thus reducing the likelihood of inward investment to deal with the legacy of industrialisation that has taken its toll on the landscape. In addition, these sites are often in densely populated areas that may have little or no provision for amenity land. Their greening can offer a relatively low cost solution for improving the aesthetic appearance and amenity resource of a region and may contribute to encouraging investment and economic growth.

One problem facing developers working in this area is that many brownfield sites contain elevated levels of contaminants including metals such as cadmium, copper, lead and zinc. These metals may originate from a range of sources including smelting, manufacturing and waste disposal operations.

Current legislation in many countries dictates that if contaminants in soils threaten to affect water quality, human or ecological health or property, remedial action must be taken. Threshold concentrations are often set which are based on soil total metal concentrations that may bear little relevance to the likelihood of any threat to the receptor of concern. It is notoriously difficult to predict the toxicological effect of a metal to vegetation, or its uptake into the plant biomass, by its total concentration in soil alone [1]. Often different species may exhibit different tolerances to the same metal or the same species may react differently under different soil conditions.

$\mathrm{Cd}$ and $\mathrm{Zn}$ represent important metals for greenspace development as they often pose different threats to the vegetation. They are metals with similar geochemical properties and are found together due to their geological associations. $\mathrm{Cd}$ is not necessary for plant growth and is often toxic to fauna at concentrations significantly lower than for vegetation. It is also mobile in soils and within the plant and may accumulate in vegetation without significantly affecting plant growth, but may pose a significant threat to primary consumers. $\mathrm{Zn}$ is an essential plant nutrient but becomes toxic to vegetation at critical levels. Both metals have previously been shown to be readily taken up by poplar species $[2,3]$.

An understanding of the uptake, compartmentation and toxicological effects of metals to trees and other vegetation is imperative if greenspace establishment on contaminated sites is to be successful and to pose no significant risk to other receptors.

This paper presents simple models of metal uptake, by one variety of poplar, which were developed based on metal spiked hydroponic trials. The validity of these models is tested using results from soil based nursery and field trials. The data will be used to indicate whether the uptake of a metal into the biomass compartments of poplar can be predicted from the bioavailable or leachable fraction of metals in the soil. 


\section{Materials and methods}

\subsection{Hydroponics trial}

The hydroponics data form part of a wider study in which the metal uptake of several varieties of poplar and willow were modelled in order to select the most suitable indicator species. This was found to be the poplar variety Fritzi Pauley (Populus trichocarpa Torr. \& Gray). In the trials plant stock consisted of $20 \mathrm{~cm}$ unrooted cuttings. The poplar cuttings were planted in sealed one litre pots containing $900 \mathrm{~cm}^{3}$ washed horticultural grade perlite. Perlite encourages good aeration and has a cation exchange capacity which is close to zero, resulting in an ion availability approaching $100 \%$ in solution. The pots were aerated with laboratory air throughout the experiment to ensure that aerobic conditions were maintained. Each pot also contained one of six solutions: control (1/4 strength Hoagland's solution [4], or one of five $\mathrm{Cd}$ or $\mathrm{Zn}$ treatments in $1 / 4$ strength Hoagland's solution. $\mathrm{Cd}$ treatments were added as $\mathrm{CdSO}_{4} \cdot 5 \mathrm{H}_{2} \mathrm{O}$ to yield

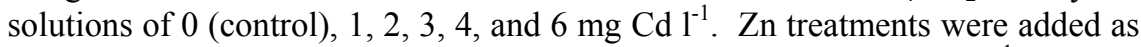
$\mathrm{ZnSO}_{4} \cdot 7 \mathrm{H}_{2} \mathrm{O}$ to yield solutions of 0.02 (control), 5, 10, and $50 \mathrm{mg} \mathrm{Zn}^{-1}$. A fully replicated randomised factorial experimental design was set up in a glasshouse and harvested after 56 days. Trees were grown under $16 \mathrm{~h}$ of artificial light (PAR) and $8 \mathrm{~h}$ darkness per day. The temperature of the glasshouse was regulated to be between $20^{\circ} \mathrm{C}$ and $30^{\circ} \mathrm{C}$. Every three days the volume of solution that had been transpired by the trees was calculated by measuring the mass lost from each pot and replenished with the appropriate solution.

\subsection{Nursery trial}

Poplar cuttings were grown in triplicate in pots containing $3.75 \mathrm{~kg}$ of a soil mixture for a period of two months. The soil had a silty-clay texture, was highly contaminated with $\mathrm{Zn}$ and also contained elevated concentrations of $\mathrm{Cd}$ (9580 mg kg${ }^{-1}$ and $128 \mathrm{mg} \mathrm{kg}^{-1}$ respectively). The soil was amended, at a range of rates, with composted garden green waste or composted sewage sludge up to $20 \%(\mathrm{w} / \mathrm{w})$. During the growing period, the water content of the soil in all pots was maintained between 0.35 and $0.5 \mathrm{~m}^{3} \mathrm{~m}^{-3}$ with the pots being allowed to freely drain to prevent anaerobic conditions. After two months of growth, the stem, shoot, leaves and roots of the poplar were harvested for analysis. Soil mixtures from the nursery trial were leached for leachable metals using a 24 hour batch extraction with a demineralised water soil ratio of 10:1 [5]. After 24 hours the water fraction was filtered through a $0.45 \mu \mathrm{m}$ filtration membrane and analysed for metals using ICP-OES.

\subsection{Field study}

Poplar cuttings were planted in a field study to assess whether the models developed using nursery data would hold true for data collected from plants growing in a contaminated soil in situ. Poplar cuttings were planted at the nodes of a $30 \times 35 \mathrm{~m}$ grid that was divided into 42 blocks each measuring $25 \mathrm{~m}^{2}$. The 
trial took place in an area of land contaminated as a result of former munitions manufacturing processes and contained heavy metal contaminants, in particular $\mathrm{Zn}\left(1040 \pm 1468 \mathrm{mg} \mathrm{kg}{ }^{-1}\right)$. Analysis of the soil concluded that it was largely composed of industrial waste and foundry sand contaminated by metals. Soil samples were taken from the locations of each poplar cutting. After 12 weeks growth the cuttings were destructively harvested for analysis. Soil samples from the field study from each planting location were taken and bioavailable metals were determined using a $0.01 \mathrm{M}$ calcium chloride extraction followed by ICP-OES analysis.

\subsection{Laboratory analyses}

Plant samples were split into their leaf and shoot components. The foliar samples were dried at $70^{\circ} \mathrm{C}$ for 24 hours before grinding with a Cyclotec mill. Samples were dry-ashed at $500^{\circ} \mathrm{C}$ and digested with a concentrated hydrochloric and nitric acid mix $(3: 1 \mathrm{v} / \mathrm{v})$. Resultant digests, leachate samples and calcium chloride extracts were analysed by ICP-OES (Spectro Analytical Instruments, West Midlands, UK) to determine concentrations of $\mathrm{Cd}$ and $\mathrm{Zn}$.

\subsection{Statistical data analysis}

Data obtained throughout this study were subjected to generalised linear regression analysis to assess the significance of changes in observation with increasing $\mathrm{Cd}$ and $\mathrm{Zn}$ concentration, using the Genstat version 8.1 [6] statistics computer software package. Where necessary, data with skewed distributions were $\log _{\mathrm{e}}$ transformed to comply with the assumptions of the regression model. Relationships between species and varieties were also studied using generalised linear regression analysis and t-probabilities of pairwise differences.

Linear and exponential models of the $\mathrm{Cd}$ and $\mathrm{Zn}$ uptake values were fitted using Genstat version 8.1 [6]. As the linear can be viewed as a limit of the exponential, the models were compared using the difference in residual sum of squares of alternative models relative to the smallest residual mean square to determine the more appropriate model. This comparison is referred to as an Fdistribution with $1, n$ degrees of freedom where $n$ is the residual degrees of freedom. When a model had been selected, the $95 \%$ confidence intervals were calculated.

\section{Results}

\subsection{Metal compartmentation}

The data suggest that $\mathrm{Cd}$ and $\mathrm{Zn}$ are compartmentalised in different ways within Fritzi Pauley (Figure 1). Whilst for both metals the concentrations in the stem tissue were lower than the other above ground plant compartments, a smaller proportion of $\mathrm{Zn}$ was present in the stem (10-22\%) than $\mathrm{Cd}(18-28 \%)$. In addition, the shoot and leaf concentrations were broadly similar for $\mathrm{Cd}$ ranging 
between 30 and $43 \%$, but for $\mathrm{Zn}$ a much higher proportion was present in the leaf tissue $(49-61 \%)$ than in the shoot tissue $(27-32 \%)$.

a)

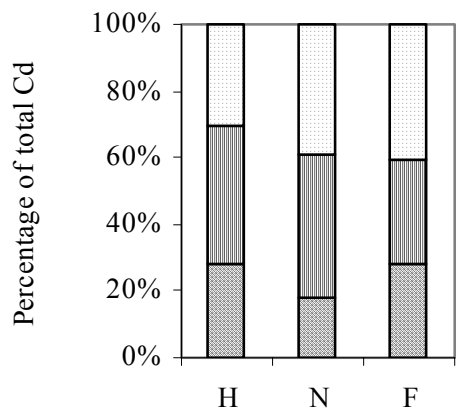

b)

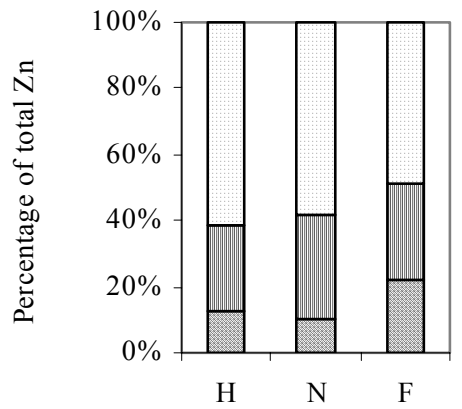

$\mathrm{H}=$ hydroponics; $\mathrm{N}=$ nursery; $\mathrm{F}=$ field; diagonal hatching=stem; vertical hatching=shoot; spots=leaf.

Figure 1: Metal compartmentation of Fritzi Pauley poplar cuttings grown in three different trials a) Cd; b) $\mathrm{Zn}$.

The proportion of $\mathrm{Cd}$ in the stem was the same in the hydroponic and field trials $(28 \%)$ and higher than in the nursery trial $(18 \%)$. The percentage in the shoot tissue was similar in the hydroponic (40\%) and nursery (43\%) trials, being higher than in the field $(32 \%)$; whilst the leaf proportions were similar in the nursery $(39 \%)$ and field $(40 \%)$ trials, being higher than the hydroponic trials $(30 \%)$. The proportion of $\mathrm{Zn}$ in the shoot tissue was broadly similar across all experimental conditions (27-32\%), as were those for stem (10-12\%) and leaf tissue (58-61\%) in the hydroponic and nursery trials. The higher percentage in stem tissue $(22 \%)$ in the field trial is reflected in a lower leaf proportion $(49 \%)$.

\subsection{Nursery and field data}

Linear regression analysis was used to determine whether the metal concentration in the leachates from the soil mixtures used in the nursery trial could be used to predict metal uptake into the plant tissues. The results show a significant positive relationship between the leachate concentration of $\mathrm{Zn}$ and the $\mathrm{Zn}$ uptake into leaf, shoot and stem of the poplar $(\mathrm{r}=0.45, \mathrm{p}<0.001 ; \mathrm{r}=0.48$, $\mathrm{p}<0.001 ; \mathrm{r}=0.24, \mathrm{p}<0.001$ respectively). Uptake of $\mathrm{Cd}$ into leaf and shoot showed no significant relation to the leachate concentration.

Linear regression analysis was used to determine whether the concentration of metals within plant tissues could be used to predict the bioavailable fraction of the soil contamination in the field. Analysis of Fritzi Pauley leaf metal concentrations showed statistically significant positive relationships with the bioavailable fraction of soil contamination for $\mathrm{Zn}(\mathrm{r}=0.33, \mathrm{p}=0.002)$ and $\mathrm{Cd}$ $(\mathrm{r}=0.37, \mathrm{p}=0.005)$. Regression analysis performed with shoot metal 
concentration again showed statistically significant positive relationships for $\mathrm{Zn}$ $(\mathrm{r}=0.27, \mathrm{p}=0.004)$ and $\mathrm{Cd}(\mathrm{r}=0.30, \mathrm{p}=0.013$.

\subsection{Metal models}

Linear or exponential models were fitted to the data produced by the hydroponics experiment. These models can be expressed as:

Cd Shoot $=(7.633 \times$ Solution concentration $)+3.85$

$$
\mathrm{r}=0.87, \mathrm{p}<0.001 \text {. }
$$

Cd Leaf $=(5.960 \times$ Solution concentration $)+3.20$

$$
\mathrm{r}=0.74, \mathrm{p}<0.001 \text {. }
$$

$\mathrm{Zn}$ Shoot $=890.9-890.9\left(0.90^{\text {Solution concentration }}\right)$ $\mathrm{r}=0.84, \mathrm{p}<0.001$.

$$
\mathrm{r}=0.86, \mathrm{p}<0.001 \text {. }
$$

where shoot and leaf concentrations are expressed as $\mathrm{mg} \mathrm{kg}^{-1}$ and solution concentrations as $\mathrm{mg} \mathrm{l}^{-1}$.

a)

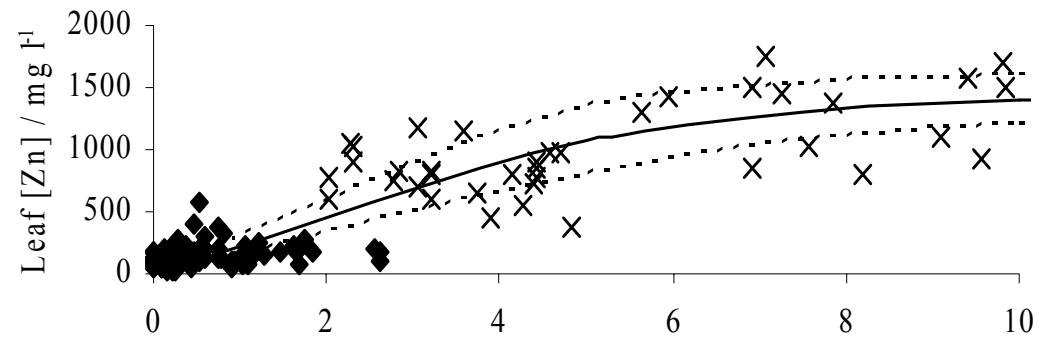

Solution $[\mathrm{Zn}] / \mathrm{mg} \mathrm{l}^{-1}$

b)

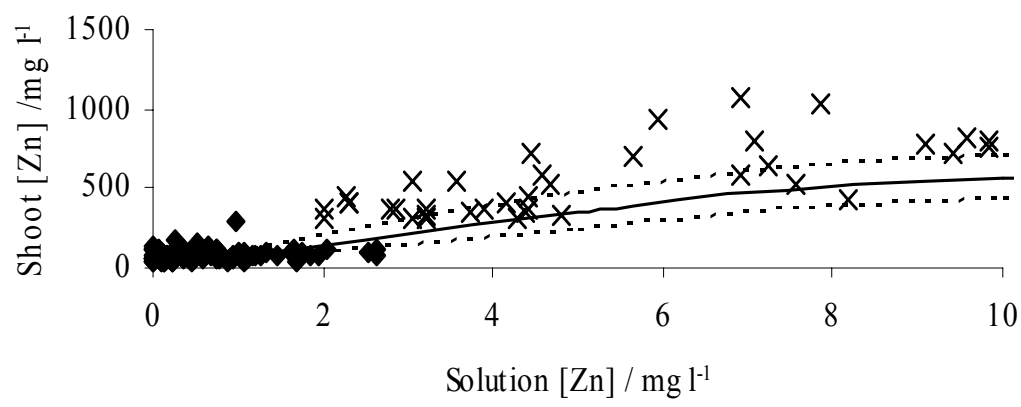

Figure 2: $\quad$ Models for Zn uptake into Fritzi Pauley a) leaf and b) shoot tissue. ( solid line $=$ model; dotted line $=$ model $95 \%$ confidence intervals; $\mathrm{x}=$ nursery data $;=$ field data). 
The significant data from the nursery and field trials were overlaid onto the models presented for $\mathrm{Cd}$ and $\mathrm{Zn}$. Whilst the $\mathrm{Cd}$ values for the field trial fitted within the $95 \%$ confidence intervals for the models the values were so low that the models could not reliably be assessed. Similarly, the $\mathrm{Zn}$ data from the field trial represented the lowest end of the $\mathrm{Zn}$ range tested in the hydroponic trial (Figure 2), although they provided a better indication of the model's validity than for $\mathrm{Cd}$. The $\mathrm{Zn}$ data from the nursery trial were generally in good agreement with the models (Figure 2). The majority of the points lay within the 95\% confidence intervals for the leaf uptake model. The shoot values from the nursery trial were generally higher than those predicted by the model; the majority falling above the upper $95 \%$ confidence interval.

\section{Discussion}

The differences observed between the way in which $\mathrm{Cd}$ and $\mathrm{Zn}$ are compartmentalised within the above ground biomass of Fritzi Pauley may be due to the different requirements the tree has for these metals. $\mathrm{Cd}$ is not an essential nutrient; therefore the plant has no mechanism for controlling its compartmentation. Conversely, $\mathrm{Zn}$ is an essential micronutrient so the plant will direct this element to the tissue in which is it needed, hence the higher proportions in the leaves. Other workers have also found higher $\mathrm{Zn}$ concentrations in the leaves of poplar compared to other compartments [7-9]. The stem is used primarily as a transport mechanism for water and nutrients within the xylem and is therefore expected to have the lowest concentrations. The differences in the way these metals are accumulated in Fritzi Pauley has implications for the potential for food-chain transfer to primary plant consumers. The accumulation of both $\mathrm{Cd}$ and $\mathrm{Zn}$ in the leaf material, compared to the concentrations within the growth medium, suggest that fauna feeding on this material would be subjected to levels much higher than the available concentrations in soil. In addition, the cycling of contaminants through leaf fall may represent a significant risk to decomposers within the soil [10].

The differences in compartmentation between the trials may be explained by a number of factors. Firstly, the levels in solution in the hydroponic trial were considerably higher than both the nursery (measured as water extractable) and field trials (measured as $\mathrm{CaCl}_{2}$ extractable). It is likely that the lower leaf proportions observed in the hydroponic trial may have resulted from a toxic effect of $\mathrm{Cd}$, which may limit transpiration reducing further uptake [11]. The highest leaf concentrations measured in the hydroponic trials were approximately $30 \mathrm{mg} \mathrm{kg}{ }^{-1}$ which are substantially higher than the normal range of $0.2-0.8 \mathrm{mg} \mathrm{kg}^{-1}$ [12], but well below the proposed upper critical concentration of $\mathrm{Cd}$ in leaf tissue of $200 \mathrm{mg} \mathrm{kg}^{-1}$ [1]. The similarities between the $\mathrm{Zn}$ compartmentation in the hydroponic and nursery trials may be due to the optimum growth conditions which the pots were grown under, in terms of light, temperature and water, than would have been experienced by the trees in the field. In addition, the higher proportions in leaf tissue may be because these trials both used $\mathrm{Zn}$ levels that resulted in tissue concentrations well above the 
$900 \mathrm{mg} \mathrm{kg}^{-1}$ critical value proposed by Dickinson [1]. The leaf concentrations in the field trial were well below this value, with a large majority falling within the 'normal' range for plant material of 8-400 $\mathrm{mg} \mathrm{kg}^{-1}$ [12]. The $\mathrm{Cd}$ and $\mathrm{Zn}$ levels in the leaf tissue at the field plot were similar to those reported by Laureysens [2] for Fritzi Pauley grown in contaminated soil. $\mathrm{Zn}$ levels were also similar to those reported in the above ground biomass of P. trichocarpa and P. nigra grown on contaminated soil [13], but much higher than those reported for poplar grown on a tannery waste with a high soil organic matter content [14]. Cd levels were substantially lower than those reported for P. trichocarpa and P. nigra grown on contaminated soil with a significantly higher Cd concentration [13]. Different species will accumulate metals at different rates $[8,9,13]$ and there is considerable variation between clones of the same species [2]. The poplars used in the field trial were in situ for a 12 week period which does not preclude the possibility of toxic levels being reached if they remained in the soil for longer time periods. It is the accumulation of metals in the leaves of vegetation over time that can result in harm to the trees and present a risk to consumers, and accumulation is likely to increase with the age of the trees [9].

The $\mathrm{Cd}$ and $\mathrm{Zn}$ levels used in the hydroponic study were above what would normally be expected in a soil solution, but were chosen to represent the range between what is 'normal' and the worst-case scenarios at contaminated sites. The mobile proportion of $\mathrm{Cd}$ and $\mathrm{Zn}$ in a contaminated soil is usually expected to be in the range of $0.5-3.2 \%$ and $4-18 \%$ respectively [13]. The $p$ values for the models show a significant relationship between metal in solution and the metal concentrations in the tissue, and the $r$ values are all high $(>0.74)$. The internal leaf concentrations in this study are in the same order of magnitude, but slightly higher than those reported in hydroponically grown red maple, white pine and Norway spruce [8]. They are also higher than those observed in a study using the poplar variety I-214, which had leaf concentrations of $131 \mathrm{mg} \mathrm{kg}^{-1}$ of $\mathrm{Zn}$ after only two additions of $1000 \mu \mathrm{M}$ solution [15].

There are a number of problems with applying data obtained from hydroponic studies to site conditions. Soil properties such as the chemical form of the metal, competing metal ions and soil $\mathrm{pH}, \mathrm{CEC}$ and organic matter will all strongly influence the availability of the contaminants to vegetation [1]. The ability of a tree to tolerate high metal levels may also vary between the nursery and field due to increased stresses in this environment. As mentioned above, trees grown in the nursery are done so under optimum conditions; the presence of these or additional stressors often found at former industrial sites, such as low organic matter or poor soil structure, may reduce metal tolerance in the field. In addition, hydroponically grown trees will not benefit from the presence of mycorrhizal fungi that may increase metal tolerance in the field [16].

Significant correlations were found between the bioavailable fraction of soil contamination and the concentration of metals within the leaves of the poplar cuttings. Calcium chloride is often used to determine the plant available fraction of soil $[1,2,17]$. The success of using this extractant is often dependant on the properties of the soil being analysed [1]. The weak relationships $(r<0.37)$ between the amount of metal extracted by calcium chloride $(0.01 \mathrm{M})$ and the 
measured plant uptake in the field study suggest that this method is not always a reliable way of assessing the potential for plant uptake.

The data for $\mathrm{Cd}$ from the nursery trial could not be overlaid onto the uptake models developed from the hydroponic work. Although, the field study data fitted into the $95 \%$ confidence intervals for the models, the $\mathrm{Cd}$ values were too low to realistically assess the reliability of the models. In contrast, the models for $\mathrm{Zn}$ uptake into the leaves and shoots can be validated using both the field and nursery data. The field leaf data are evenly spread around the base of model and the majority of the nursery results fitted within the $95 \%$ confidence interval of the model. $\mathrm{Zn}$ uptake in the shoots is similar for field results but the nursery results are only partly within $95 \%$ confidence interval, tending to show increased uptake compared to the hydroponic study. In summary, $\mathrm{CaCl}_{2}$ extractable soil metals give significant but weak correlations against metal uptake into the leaves of poplar. However, this study demonstrates that it may be possible to use leaf concentrations of Fritz Pauley poplar grown as a bioindicator to assess the plant available concentration of zinc in soil. Such data can then be applied to models derived from hydroponic studies of metal uptake for other tree species to predict their likely survival, growth, and metal uptake characteristics and associated risk of food chain transfer.

\section{Conclusion}

The application of poplars as indicators of the plant available fraction of soil may provide a valuable tool to be used in conjunction with standard soil analysis techniques. The application of models to predict the available $\mathrm{Zn}$ concentration in soil using leaf concentrations looks promising. In contrast, the models for $\mathrm{Cd}$ need to be compared to Fritzi Pauley grown on soils with higher available levels of $\mathrm{Cd}$ before their validity can be truly assessed.

\section{References}

[1] Dickinson, N.M., Mackay, J.M., Goodman, A. \& Putwain, P., Planting trees on contaminated sites: Issues and guidelines. Land Contamination and Reclamation, 8(2), pp. 87-101, 2000.

[2] Laureysens, I., Blust, R., de Temmerman, L., Lemmens, C. \& Ceulemans, $\mathrm{R}$., Clonal variation in heavy metal accumulation and biomass production in a poplar coppice culture: I. Seasonal variation in leaf, wood and bark concentrations. Environmental Pollution, 131, pp. 485-494, 2004.

[3] Madejón, P., Marañón, T., Murillo, J.M. \& Robinson, B., White poplar (Populus alba) as a biomonitor of trace elements in contaminated riparian forests. Environmental Pollution, 132, pp. 145-155, 2004.

[4] Hoagland, D.R., \& Arnon, D.I., The water-culture method for growing plants without soil. Miscellaneous Publications No. 3514. California Agricultural Experiment Station, California, 1941. 
[5] BSI, Characterisation of waste - Leaching - Compliance test for leaching of granular waste materials and sludges. BS En 12457: Part 2, British Standards Institution, London, 2002.

[6] GenStat, The Guide to GenStat Release 8.1 Part 2: Statistics, ed. R.W. Payne, Lawes Agricultural Trust, Rothamsted Experimental Station, VSN International: Oxford, 2005.

[7] Pulford, I.D. \& Watson, C., Phytoremediation of heavy metalcontaminated land by trees - a review. Environment International, 29, pp. 529-540, 2003.

[8] Mitchell, C.D. \& Fretz, T.A., Cadmium and zinc toxicity in white pine, red maple and Norway spruce. Journal of the American Society of Horticultural Science, 102(1), pp. 81-84, 1977.

[9] Hermle, S., Günthhardt-Goerg, M.S. \& Schulin, R., Effects of metalcontaminated soil on the performance of young trees going in model ecosystems under field conditions. Environmental Pollution, in press.

[10] Hobbelen, P.H.F., Koolhaas, J.E. \& van Gestel, C.A.M., Effects of heavy metals on the litter consumption by the earthworm Lumbricus rubellus in field soils. Pedobiologia, 50, pp. 51-60, 2006.

[11] Lamoreaux, R.J. \& Chaney, W.R., Growth and water movement in silver maple seedlings affected by cadmium. Journal of Environmental Quality, 6(2), pp. 201-205, 1977.

[12] Ross, S. M., Sources and forms of potentially toxic metals in soil-plant systems. Toxic Metals in Soil-Plant Systems, ed. S.M. Ross, John Wiley \& sons: Chichester, pp. 2-27, 1994.

[13] Fischerová, Z., Tlustoš, P., Száková, J. \& Šichorová, K., A comparison of phytoremediation capability of selected plant species for given trace elements. Environmental Pollution, in press.

[14] Giachetti, G. \& Sebastiani, L., Metal accumulation in poplar grown with industrial wastes. Chemosphere, in press.

[15] Di Baccio, D., Tognetti, R., Sebastiani, L. \& Vitagliano, C., Responses of Populus deltoides x Populus nigra (Populus x euramericana) clone I-214 to high Zn concentrations. New Phytologist, 159, pp. 443-452, 2003.

[16] Kim, C.-G., Power, S.A. \& Bell, J.N.B., Effects of host plant exposure to $\mathrm{Cd}$ on mycorrhizal infection and soluble carbohydrate levels of Pinus sylvestrus seedlings. Environmental Pollution, 131, pp. 287-294, 2004.

[17] Young, S.D., Zhang, H., Tye, A.M., Maxted, A., Thums, C. \& Thornton, I., Characterising the availability of metals in contaminated soil. I. The solid phase: sequential extractions and isotopic dilution. Soil Use and Management, 21, pp. 450-458, 2006. 